\title{
Motherlove
}

\section{Clair Cafaro}

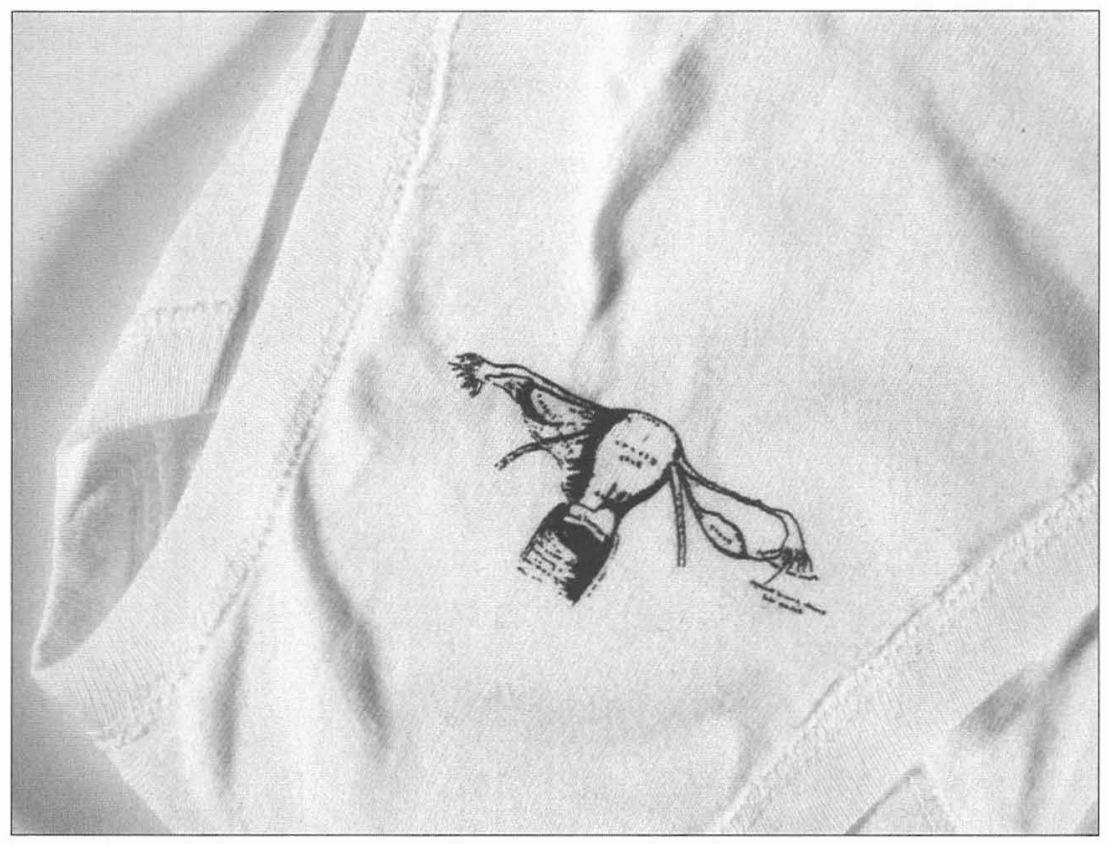

Daughter, detail, cotton diaper shirt, silk-screen, $7^{\prime \prime} \times 12^{\prime \prime}$, Dec.' 97

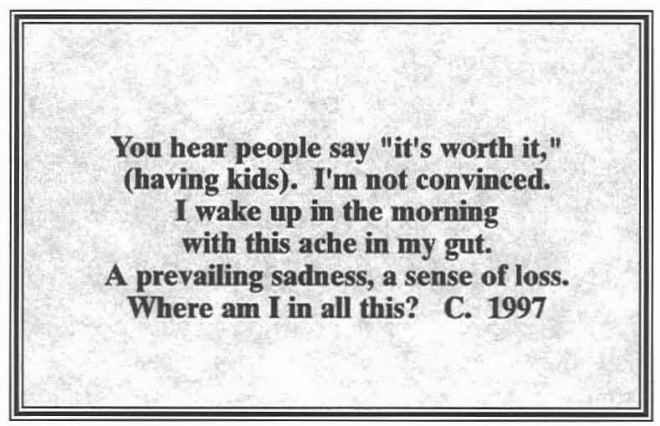



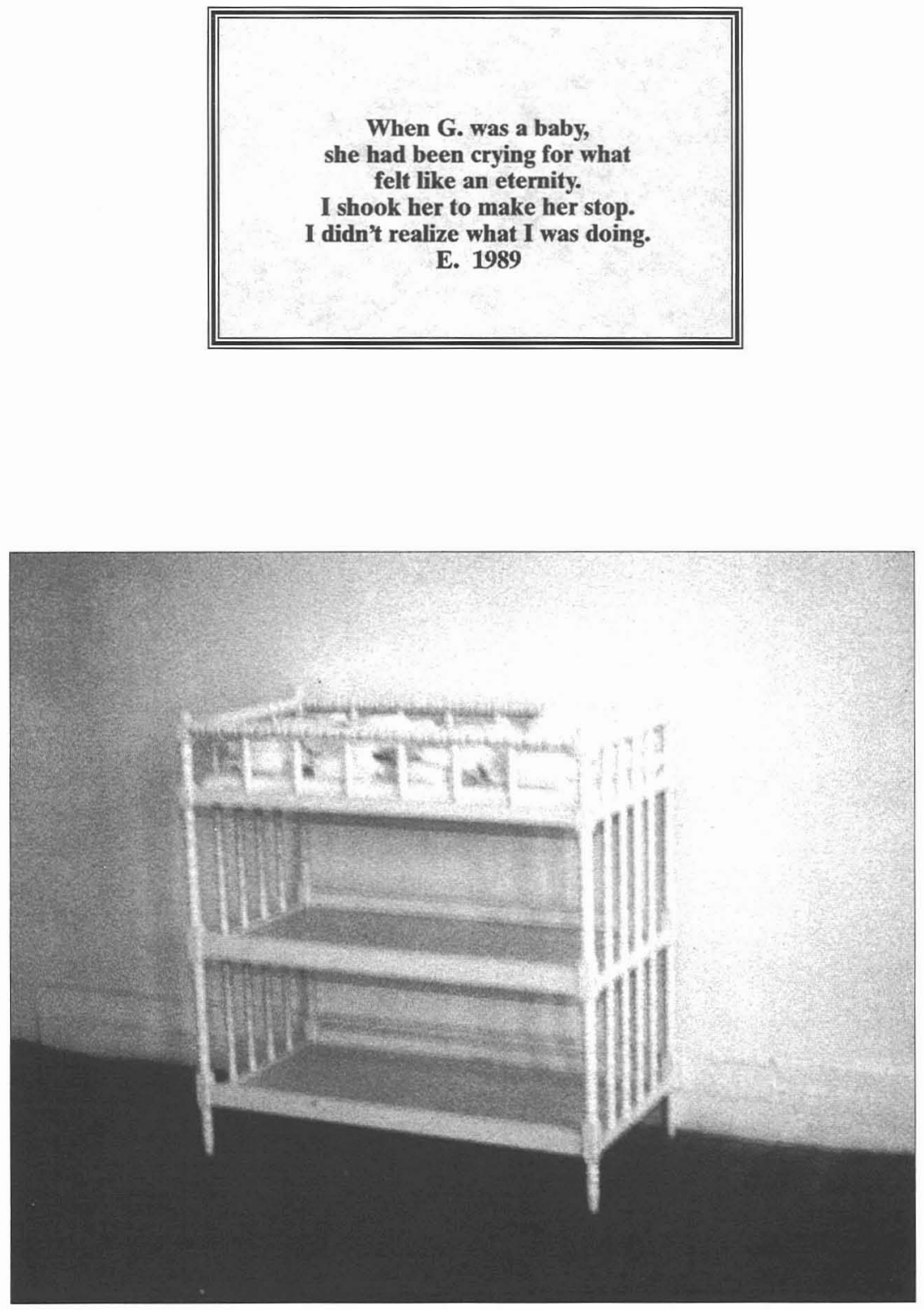

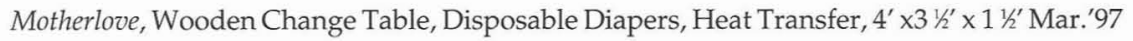




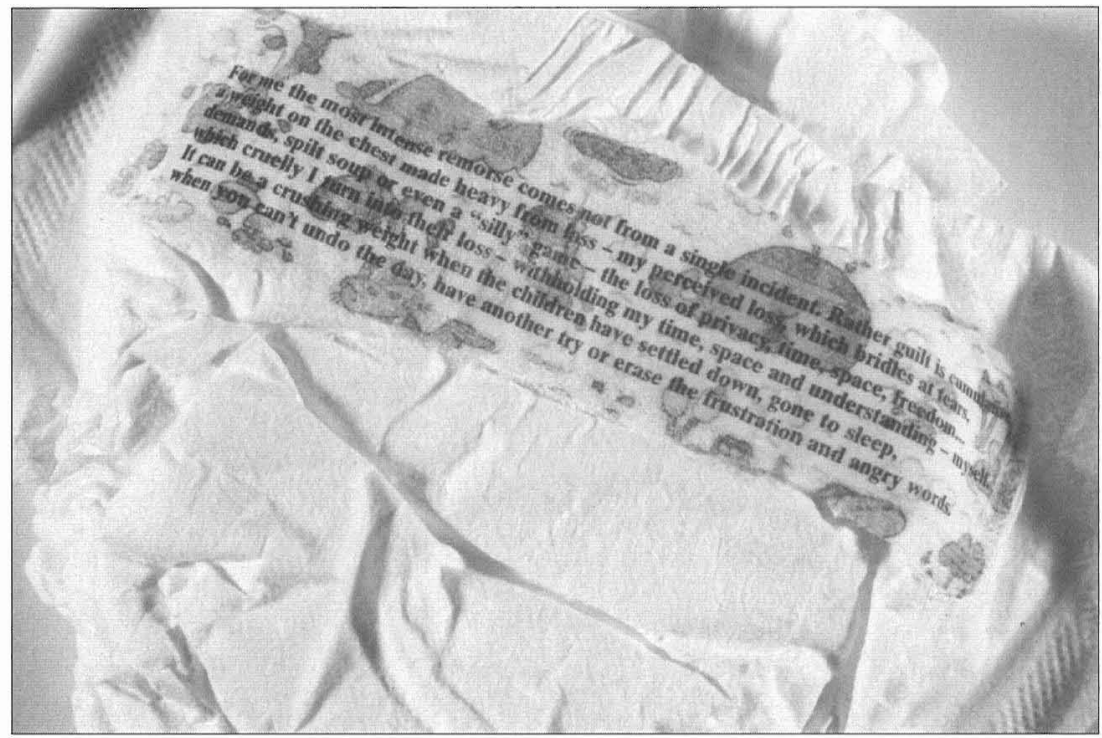

Motherlove, detail, cotton diaper shirt, silk-screen, 7" x 12", Dec.'97

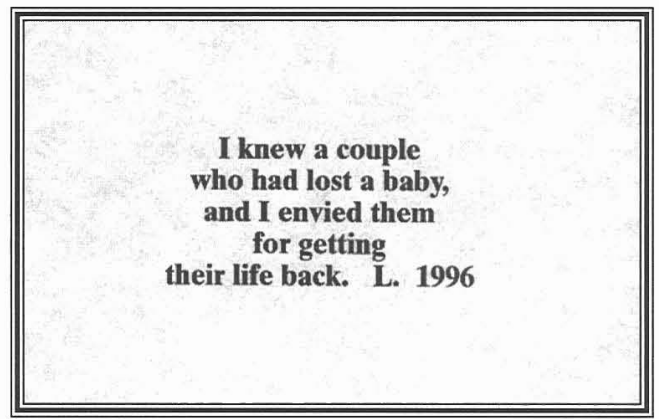

